\title{
Catalytic Fixed-Bed Pyrolysis of Lignocellulosic Biomass for Production of Phenolic-Rich Bio-Oil
}

\author{
Alisa Mamaeva ${ }^{1, a}$, Arash Tahmasebi ${ }^{1, b}$ and Jianglong $\mathrm{Yu}^{1,2, \mathrm{c}}$ \\ ${ }^{1}$ Key Laboratory of Advanced Coal and Coking Technology of Liaoning Province, School of \\ Chemical Engineering, University of Science and Technology Liaoning, Anshan (114051), \\ People's Republic of China \\ ${ }^{2}$ Chemical Engineering, University of Newcastle, Callaghan, NSW 2308, Australia \\ aalisita.m@mail.ru, barashtahmasebi@163.com, cjianglongyu@163.com (corresponding author)
}

Keywords: lignocellulosic biomass, phenols, activated carbon, catalytic pyrolysis, fixed-bed

Abstract. Production of fine chemical from biomass has attracted increasing research attention in recent years. In this paper, the effects of activated-carbon on production of phenolic-rich bio-oil were systematically studied. Different ratios of the activated carbon/peanut shell in the blend were pyrolyzed and the bio-oil was analyzed using GC-MS technique. The analyses showed that the addition of activated carbon improved both bio-oil yield and the concentration of phenolic compounds in the liquid product. The bio-oil yield reached to $21.42 \mathrm{wt}$ \% and containing $49.91 \%$ (by area) phenolic compounds.

\section{Introduction}

The depletion of fossil fuels and their adverse environmental impact demands the exploration of new energy resources. Biomass is one of the most promising renewable energy sources in the near future [1]. However, biomass has also been realized as one of the most significant sustainable replacements for petroleum based fuels for production of value-added chemicals. Currently, bio-oil derived from biomass pyrolysis has drawn increasing attention as an alternative source for fuels and chemicals. Potential bio-based chemicals from bio-oil include phenolics and cyclic ketones for resins and solvents, levoglucosan and levoglucosenon for polymers, and aromatic hydrocarbons for fuels and solvents [2]. Biomass is highly functionalized organic material. New mechanistic insights is necessary to develop efficient methods for chemical depolymerization for selective production of fine chemicals from biomass [3].

Among biomass constituents, lignin is a promosing source of aromatic fine chemicals. Lignin (10-25 wt.\% of biomass) is an aromatic polymer that decomposes at $280-500{ }^{\circ} \mathrm{C}$ to produce phenolic compounds. Pyrolysis, a thermochemical conversion process, is an attractive way to produce fine chemicals from solid biomass feedstock. Biomass pyrolysis faces some technical challenges. The bio-oil produced from pyrolysis of biomass is complex in chemical composition and highly unstable [4]. Although much progress has been made in the production of bio-oils, especially from lignocellulosic biomass sources [5], currently these oils cannot be used directly as fuels due to their high oxygen content, corrosive nature, high viscosity, and relative instability. Consequently, prior to their use as fuels, these bio-oils must be chemically upgraded (typically via cracking and/or hydrotreating) and further purified in additional costly and time-consuming steps [6, 7]. However, these complications can be minimized and potentially circumvented altogether through the incorporation of appropriate catalysts directly into the pyrolysis process in order to upgrade the pyrolysis products in situ.

In this study, the effect of addition of activated carbon to peanut shell during fixed-bed pyrolysis on the yield of pyrolysis products and concentration of phenolic compounds in the bio-oil was investigated. The effect of process parameters such as temperature and biomass/catalyst ratio was also systematically studied. The composition of bio-oil was analyzed using Gas Chromatography-Mass Spectroscopy (GC-MS). 


\section{Experimental}

Materials. Peanut shell used in this study was from North China. As-received biomass sample was crushed and sieved to particle size of $125-250 \mu \mathrm{m}$. The sample was dried in a vacuum oven at $105^{\circ} \mathrm{C}$ prior to pyrolysis runs to remove the moisture. The proximate and ultimate analyses of the peanut shell sample are given in Table 1 . As-received activated carbon was dried in a vacuum oven at $105^{\circ} \mathrm{C}$ and used as catalyst in the fixed-bed pyrolysis experiments.

Table 1. Proximate and ultimate analyses of peanut shell

\begin{tabular}{cc}
\hline Item & Value \\
\hline Moisture, [ar, wt.\%] & 8.03 \\
Volatile matter, [ar, wt.\%] & 58.38 \\
Fixed carbon, [ar, wt.\%] & 22.29 \\
Ash, [ar, wt.\%] & 11.31 \\
C, [daf, wt.\%] & 37.87 \\
H, [daf, wt.\%] & 5.18 \\
N, [daf, wt.\%] & 1.57 \\
S, [daf, wt.\%] & 0.14 \\
$\mathrm{O}^{\mathrm{a}}$, [daf, wt.\%] & 55.24 \\
\hline
\end{tabular}

a: calculated by difference; b: molar ratio; ar: as received; daf: dry ash free

Fixed-bed pyrolysis experiments. Pyrolysis experiments were performed in a vertical fixed-bed tubular quartz reactor with the inner diameter of $20 \mathrm{~mm}$ heated in an electric furnace. The initial biomass feed was $3 \mathrm{~g}$ in each experimental run. Pure biomass was pyrolyzed at pyrolysis temperatures ( $300,400,500$, and $600^{\circ} \mathrm{C}$ ) to study the effect of temperature on product yields and bio-oil composition. Catalytic pyrolysis experiments were carried out at $400^{\circ} \mathrm{C}$ using four ratios of activated carbon (AC) to biomass (0.3:3, 0.4:3, 0.5:3, 0.6:3). AC was physically mixed with the biomass and loaded into the quartz fixed bed reactor. Nitrogen was used as a carrier-gas. Prior to the each run, the entire pyrolysis set-up was purged with nitrogen at $100 \mathrm{ml} / \mathrm{min}$ flow rate for 30 minutes to ensure an inert atmosphere achieved. When the desired temperature reached, reactor was placed into the furnace and pyrolysis was carried out for 40 minutes with the nitrogen flow of $100 \mathrm{ml} / \mathrm{min}$. The evolved bio-oil was condensed in four condensers loaded with dichloromethane and placed in ice bath. Chars and liquid products were directly weighed and the gas yield was measured by difference. Reproducibility was ensured by replicated runs and the experimental error ranged between $\pm 5 \%$ of the average value. The yields of pyrolysis products were calculated based on the method described elsewhere [8].

Bio-oil characterization. Bio-oil was separated from dichloromethane by distillation. The bio-oil fraction obtained was further analyzed by Gas Chromatography-Mass Spectrometry (GC-MS, Thermo Scientific ISQ). The GC-MS was equipped with a capillary column coated with TR-5MS (cross-link 5\% Phenyl (equiv.) Polysilphenylene-siloxane, $30 \mathrm{~m}$ length, $0.25 \mathrm{~mm}$ inner diameter, 0.25 $\mu \mathrm{m}$ film thickness) and a quadrupole analyzer operating in electron impact (70 eV) mode. The oven was heated at $10{ }^{\circ} \mathrm{C} / \mathrm{min}$ from 40 to $100{ }^{\circ} \mathrm{C}$, and then at a rate of $15^{\circ} \mathrm{C} / \mathrm{min}$ from 100 to $280{ }^{\circ} \mathrm{C}$, and held at $280^{\circ} \mathrm{C}$ for 15 minutes. The data were acquired and processed using the Chemstation software. The compounds were identified by comparing their mass spectra to spectral data in the instrument database.

\section{Results and Discussion}

Non-catalytic pyrolysis experiments. Table 2 shows the product yields from fixed-bed pyrolysis of peanut shell as a function of temperatures during non-catalytic experiments. Table 2 also shows the product yields from catalystic pyrolysis of peanut shell using activated carbon at four different blending ratios. As seen, in non-catalytic experiments the bio-oil yield reached to its maximum at $500{ }^{\circ} \mathrm{C}$ (25.72 wt.\%). Fig. 1 shows the chemical composition of bio-oil as a function of temperature during non-catalytic experiments. The produced bio-oil was a mixture of a wide range of chemical compounds. The concentration of phenolic compounds in bio-oil reached to its maximum (32.14 
area\%) at $400{ }^{\circ} \mathrm{C}$. Although slightly higher bio-oil was observed achieved at $500{ }^{\circ} \mathrm{C}$, the concentration of phenolic compounds at $500{ }^{\circ} \mathrm{C}$ was only 22.79 area $\%$ and was lower than that of $400{ }^{\circ} \mathrm{C}$. Therefore, catalytic pyrolysis experiments were carried out at $400{ }^{\circ} \mathrm{C}$.

Fig. 1 also shows that with increasing the pyrolysis temperature, the concentration of polycyclic aromatic compounds, hydrocarbons, and benzene derivatives in bio-oil increased. The concentration of alcohols reached to its highest yield at $400{ }^{\circ} \mathrm{C}$ and decreased thereafter.

Table 2. Yields of pyrolysis products of peanut shell under different temperatures and with different activated carbon ratios

\begin{tabular}{ccccc}
\hline Sample & Temperature $\left({ }^{\circ} \mathrm{C}\right)$ & Char (wt.\%) & Liquid (wt.\%) & Gas (wt.\%) \\
\hline & 300 & 51.19 & 12.99 & 35.82 \\
Peanut shell & 400 & 39.00 & 14.63 & 46.37 \\
& 500 & 41.17 & 25.72 & 33.11 \\
\hline Activated carbon to & 600 & 42.60 & 22.60 & 34.80 \\
peanut shell ratio & & & 25.23 & 29.29 \\
\hline $0.3: 3$ & & 46.48 & 29.51 & 24.22 \\
$0.4: 3$ & 400 & 46.27 & 21.42 & 35.36 \\
$0.5: 3$ & & 43.22 & 27.21 & 23.4 \\
$0.6: 3$ & & 49.39 & & \\
\hline
\end{tabular}

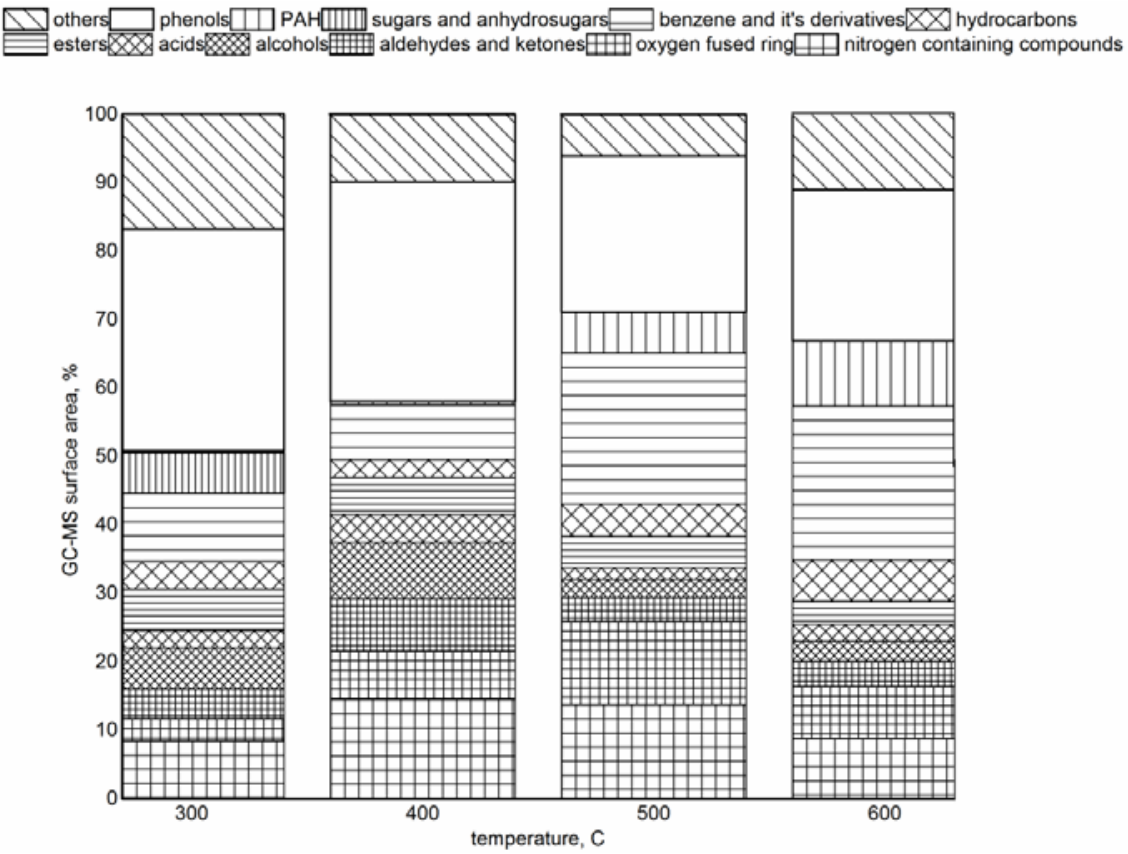

Fig. 1. Chemical composition of bio-oil from non-catalytic pyrolysis of peanut shell

Catalytic pyrolysis experiments. Catalytic pyrolysis experiments were carried out at $400^{\circ} \mathrm{C}$ and at different activated carbon/biomass ratios. Table 2 shows that the addition of activated carbon to biomass during pyrolysis resulted in a significant increase in bio-oil yield. At $400^{\circ} \mathrm{C}$, the liquid yields of 25.23, 29.51, 21.42, and 27.21wt.\% were obtained at activated carbon/peanut shell blending ratios of $0.3: 3,0.4: 3,0.5: 3$, and $0.6: 3$, respectively. The highest bio-oil yield was obtained at activated carbon/biomass ratio of 0.4:3 (29.51 wt.\%). Chemical composition of bio-oil obtained from catalytic pyrolysis experiments is shown in Fig. 2. The use of activated carbon as catalyst during the fixed-bed pyrolysis experiments resulted in a significant increase in formation of phenolic compounds. The concentration of phenolics reached to its highest value (49.91 area\%) using activated carbon/peanut shell ratio of 0.5:3. Bio-oils obtained from catalytic pyrolysis experiments in all cases contained higher phenolic compounds compared to non-catalytic experiments. Phenolic compounds reached to 42.97, 43.45, 49.91, and 48,05 area\% at 0.3:3, 0.4:3, 0.5:3, and 0.6:3 AC to peanut shell ratios, 
respectively, as given in table 2. Unlike bio-oil from non-catalytic pyrolysis, no PAHs were observed in catalytic bio-oil.

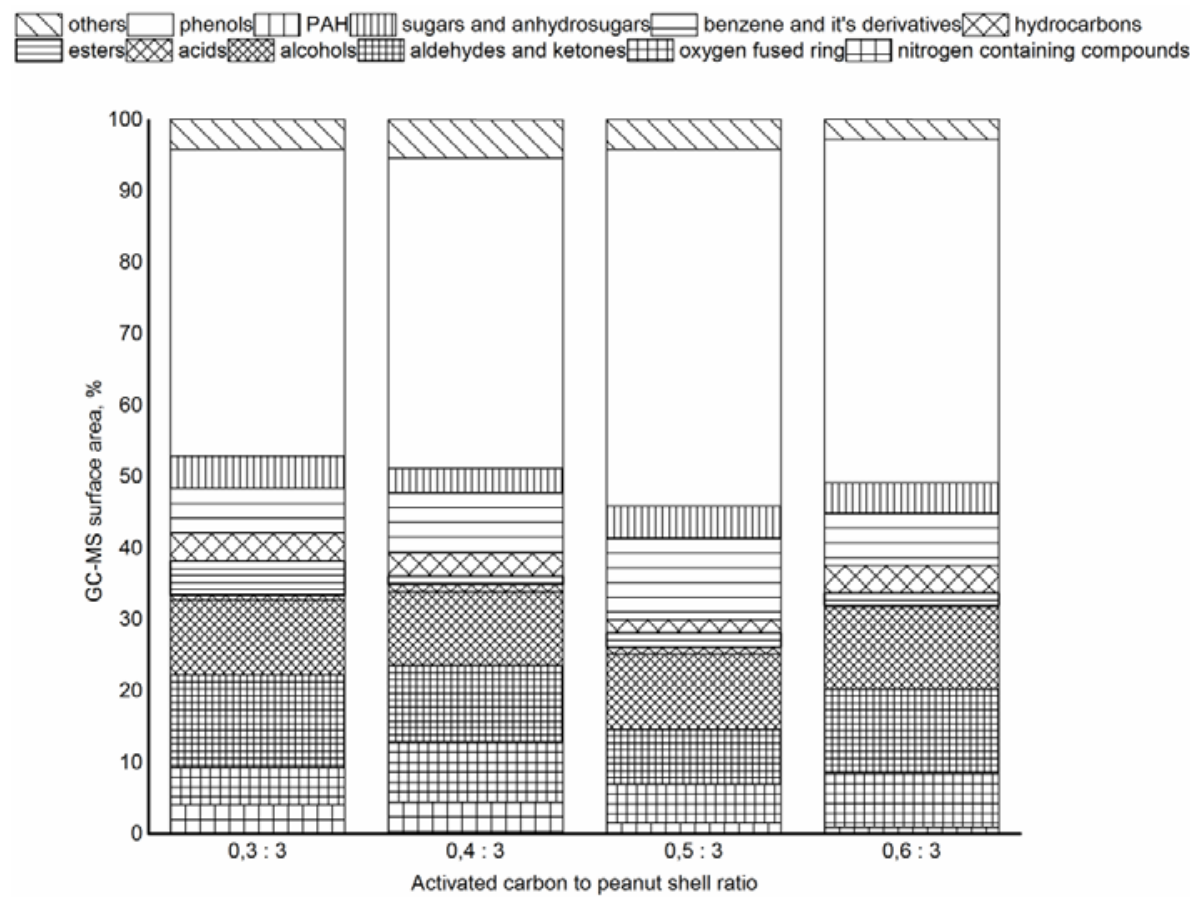

Fig. 2. Chemical composition of catalytically obtained bio-oils for different AC: peanut shell ratios

\section{Summary}

High yield of phenolic compounds was achieved through catalytic fixed-bed pyrolysis of lignocellulosic biomass using activated-carbon as catalyst. Activated-carbon increased the total yield of bio-oil. The highest bio-oil yield was obtained at activated carbon/biomass ratio of 0.4:3 (29.51 wt.\%). Activated carbon increased the selectivity of phenolic compounds in bio-oil. The concentration of phenols reached to the highest value using activated carbon/peanut shell ratio of 0.5:3.

\section{Acknowledgements}

This study was supported by the Natural Science Foundation of China (21176109, U1361120, and 21476100).

\section{References}

[1] N. Wang, A. Tahmasebi, J. Yu, J. Xu, F. Huang and A. Mamaeva, Bioresour. Technol. Vol. 190 (2015), p. 89.

[2] K. D. Maher and D. C. Bressler, Bioresour. Technol. Vol. 98 (2007), p. 2351.

[3] K. Barta and P. C. Ford, Accounts Chem. Res. Vol. 74 (2014), p. 1503.

[4] Y. Wan, P. Chen, B. Zhang, C. Yang, Y. Liu, X. Lin and R. Ruan, J. Anal. Appl. Pyrol. Vol. 86 (2009), p. 161.

[5] J.-S. Kim, Bioresour. Technol. Vol. 178 (2015), p. 90.

[6] Y. Wang, X. Hu, Y. Song, Z. Min, D. Mourant, T. Li, R. Gunawan and C.-Z. Li, Fuel Process. Technol. Vol. 116 (2013), p. 234.

[7] R. Gunawan, X. Li, C. Lievens, M. Gholizadeh, W. Chaiwat, X. Hu, D. Mourant, J. Bromly and C.-Z. Li, Fuel Vol. 111 (2013), p. 709.

[8] T. Yuan, A. Tahmasebi and J. Yu, Bioresour. Technol. Vol. 175 (2015), p. 333. 